\title{
Processo de diagnóstico da surdez em crianças na percepção de familiares e gestores
}

\section{Process diagnosis of deafness in children in the perception of familiar and managers}

Luciana Santos Gerosino da Silva', Claudia Giglio de Oliveira Gonçalves

\begin{abstract}
RESUMO
Objetivo: Analisar a percepção de familiares e gestores (educação e saúde) sobre o processo de diagnóstico da surdez em crianças de um município do Paraná. Métodos: A coleta de dados deu-se a partir da técnica de grupo focal formado por dez pais e por entrevista aberta individual com gestores. A análise do material extraído foi feita por meio do estudo do conteúdo na modalidade temática. A discussão dos dados foi organizada pela análise das falas dos sujeitos. Resultados: Foi possível extrair duas grandes categorias temáticas: frustração no processo de diagnóstico, acolhimento e orientação; dificuldades na relação intersetorial Saúde e Educação. Conclusão: Os desdobramentos da surdez diagnosticada tardiamente permearam os âmbitos relacionados à saúde e à educação das crianças com surdez. O diagnóstico precoce e o acolhimento adequado não ocorreu na maioria das crianças e verificou-se que a relação intersetorial (saúde e educação) é insatisfatória.
\end{abstract}

Descritores: Saúde Pública; Diagnóstico Precoce; Fonoaudiologia; Perda Auditiva; Surdez; Pais; Serviços de Saúde

\begin{abstract}
Purpose: To analyze the perception of family and managers (education and health) on the process of diagnosis of deafness in children in a city in Paraná. Methods: The analysis of the material gathered in the focus groups and on the interviews was made based on the analysis of content of the thematic mode. The discussion of the data was organized based on the analysis of the subjects' testimonies. Results: The thematic categories were: the early diagnosis and hearing health as a human right; and the necessity of adequate support and initial guidance; challenges in the inter-sector and inter-network relations. Conclusion: We have reached the conclusion that the repercussions of a late deafness diagnosis have influence in health and education aspects of the deaf children's life. Early diagnosis and adequate support did not happen with the majority of the children. An inadequate inter-sector relation between Health and Education municipal authorities was verified.
\end{abstract}

Keywords: Public Health; Early Diagnosis; Speech, Language and Hearing Sciences; Hearing Loss; Deafness; Parents; Health Services

Trabalho realizado na Universidade Tuiuti do Paraná - UTP - Tuiuti - Curitiba (PR), Brasil.

(1) Programa de Mestrado e Doutorado em Distúrbios da Comunicação, Universidade Tuiuti do Paraná - UTP - Curitiba (PR), Brasil.

Conflito de interesses: Não

Contribuição dos autores: $L S G S$ pesquisador principal, elaboração da pesquisa, elaboração do cronograma, levantamento da literatura, coleta e análise dos dados, redação do artigo, submissão e trâmites do artigo; $C G O G$ orientadora, elaboração da pesquisa, elaboração do cronograma, análise dos dados, correção da redação do artigo, aprovação da versão final.

Endereço para correspondência: Luciana Santos Gerosino da Silva. R. Coronel Inácio Taborda Ribas, 893, Bigorrilho, Curitiba (PR), Brasil, CEP: 80730-330. E-mail: luquitafono@gmail.com

Recebido em: 2/1/2013; Aceito em: 14/10/2013 


\section{INTRODUÇÃO}

Levantamento demográfico realizado pelo Instituto Brasileiro de Geografia e Estatística ${ }^{(1)}$ constatou que 45.606.048 milhões de pessoas declararam ter, pelo menos, uma das deficiências investigadas e isso corresponde a 23,9\% da população brasileira. A deficiência auditiva foi citada por $36,2 \%$ da população e, desse percentual, $1,3 \%$ encontra-se na faixa etária de 0 a 14 anos. Entre a população acometida, as crianças inscritas nas faixas etárias inferiores a 15 anos, apresentam perda auditiva permanente, sendo que dois terços, cerca de 41 milhões, habitam países em desenvolvimento ${ }^{(2)}$. Em neonatos, a incidência de deficiência auditiva é de 1,5 a 5,95 por 1.000 nascimentos e as causas, muitas vezes, poderiam ser evitadas ${ }^{(3)}$.

Sendo assim, a surdez infantil é considerada um problema de saúde pública, devido a sua elevada prevalência e também às múltiplas consequências que impedem o desenvolvimento infantil saudável.

Sabe-se que a privação sensorial nos primeiros anos de vida poderá acarretar dificuldades na aquisição da fala e da linguagem, interferindo no processo do desenvolvimento do pensamento, da inteligência e do raciocínio, como também na formação do individuo como um todo e até em seu processo de escolarização. Tais fatos colocam em evidência a necessidade do diagnóstico precoce e a efetivação de programas de triagem auditiva em todas as crianças nascidas no território nacional ${ }^{(4)}$.

O reconhecimento da deficiência auditiva como problema de saúde pública impulsionou a criação de políticas públicas de saúde, direcionadas à minimização de seus impactos na vida das pessoas. Estendendo-se a discussão sobre os cuidados em saúde, com base em princípios do Sistema Único de Saúde, tais como a universalidade, equidade e integralidade nos cuidados em saúde para população com risco de deficiência auditiva e surdez, foi instituída, em 2004, a Política Nacional de Atenção à Saúde Auditiva (PNASA) ${ }^{(5)}$. A portaria preconiza a implantação de redes estaduais, responsáveis por realizar ações integrais de promoção e prevenção, diagnóstico audiológico, concessão de próteses auditivas, acompanhamento e reabilitação ${ }^{(5)}$.

A referida proposta está clara e em vigor. Contudo, é necessário avaliar, na perspectiva de seus participantes, como ocorre a sua implementação, mais especificamente, quais as repercussões do diagnóstico audiológico. Há duas categorias que participam diretamente do processo de diagnóstico: de um lado, os pais de crianças surdas, que utilizam o sistema e, de outro, os gestores, que planejam e avaliam o processo de implantação e execução das intervenções advindas da política.

Tendo em vista tais considerações, este estudo teve como objetivo analisar a percepção de familiares e gestores (educação e saúde) sobre o processo de diagnóstico da surdez em crianças de um município do Paraná.

\section{MÉTODOS}

Trata-se de um estudo de natureza qualitativa. O local da pesquisa foi o Centro de Atendimento Educacional Especializado, localizado na região metropolitana de Curitiba (PR), referência em atendimento aos deficientes auditivos e visuais, constituindo a rede de serviços de Educação Especial da Secretaria Municipal de Educação, com professores capacitados e um profissional de fonoaudiologia.

O centro é frequentado por 100 estudantes de diversas faixas etárias, sendo que 80 apresentam alterações visuais e 20, alterações auditivas. Dos 20 referidos, 18 possuem perda auditiva neurossensorial de grau profundo, bilateralmente (surdez bilateral), e dois, perda auditiva neurossensorial de grau severo à profundo, bilateralmente. Os alunos que frequentam a escola regular, em contraturno, participam de programas que têm como objetivo desenvolver habilidades que favorecerão o processo de aprendizagem, o desenvolvimento da linguagem, os processos cognitivos e perceptuais, a socialização e a autonomia.

Tais programas abrangem: estimulação precoce e atendimento educacional especializado, atuando através de técnicas específicas ao ensino-aprendizagem para educandos cegos; o apoio educacional bilíngue, pedagógico e fonoaudiológico ao deficiente auditivo e visual; estimulação visual, sorobã/matemática; confecções de materiais adaptados; aulas de artesanato; atividades de vida diária; orientação e mobilidade; educação física; aulas de informática; aulas de LIBRAS com instrutora surda; intérprete de LIBRAS e orientação familiar.

O critério de inclusão para este estudo foi: serem pais e/ou cuidadores de crianças que iniciaram o acompanhamento no centro de atendimento educacional a partir de 2004 (ano em que a Política Nacional de Atenção à Saúde Auditiva foi instituída nacionalmente). Foram excluídos da pesquisa os pais e/ou cuidadores de crianças que ingressaram no centro após esse ano.

Assim, foram sujeitos elegíveis desta pesquisa, dez pais e/ou cuidadores (família) dos estudantes com surdez bilateral, independente da idade cronológica e da época do diagnóstico de surdez.

Os critérios para a escolha dos gestores foram o cargo, a disponibilidade e a responsabilidade. Participaram dois gestores, um representando o Setor Educação e que atuava no núcleo regional de educação da área metropolitana norte do Paraná, sendo responsável pelas áreas de surdez, deficiência visual e deficiência física neuromotora e outro, representando o Setor Saúde e que ocupava o cargo de coordenador da Saúde da Criança do município.

Desse modo, os sujeitos compuseram dois grupos: Grupo 1: Família - constituído por e/ou responsáveis pelos alunos surdos e Grupo 2: Gestores - que representavam e compunham as Secretarias de Educação e Saúde. Os participantes apresentavam a problemática da surdez como ponto em comum em suas vivências, cada um deles com seu olhar e sua perspectiva diante das dificuldades desde o diagnóstico, condutas e escolarização. 
Vale ressaltar que eram oito crianças com surdez, pertencentes a oito famílias. Porém, compareceram, como responsáveis, dois pais acompanhados pelas respectivas mães e um pai sem a respectiva mãe, totalizando dez sujeitos no Grupo 1- Família.

Como artifício facilitador e recurso mantenedor do sigilo dos participantes, foram representados pela inicial do grupo a que pertenciam (Grupo 1 (Família) - G1; Grupo 2 (Gestores) - G2, acrescida de uma codificação correspondente ao participante (G1 Família - F1; G2 Gestor - G2). À codificação para diferenciar o sujeito (pai ou mãe) foi acrescentado o numeral ordinal (1) após o código que corresponde ao participante (ex: F5 - mãe; F5.1 - pai).

O recurso metodológico utilizado foi a estratégia do grupo focal, pois volta-se para um determinado foco, que consiste na problemática em questão e que o grupo irá discutir nas suas mais diversas dimensões possíveis, dentro de um processo interacional. Além disso, também foi utilizado o recurso de entrevista individual com os gestores.

O grupo focal foi composto por dez sujeitos (pais e/ou cuidadores) que apresentavam características e posição social semelhantes, como é recomendado na literatura ${ }^{(6)}$. Foram realizados dois encontros com todos os sujeitos, com uma hora e meia de duração e em datas distintas do mês de fevereiro de 2012, em ambiente acolhedor - a sala de reunião do centro de atendimento educacional. O moderador-pesquisador conduziu as discussões, mantendo o foco. Outro pesquisador fez a gravação do áudio e anotações pertinentes. Para que fosse possível perceber o domínio dos pais em relação à surdez, a pergunta disparadora às famílias dos grupos focais foi: "Como foi $o$ processo de diagnóstico de surdez do seu filho?”. Vale ressaltar que alguns pais não se posicionaram em determinados assuntos e por isso seus relatos não constaram nos recortes.

A técnica de entrevista individual aplicada ao gestor foi escolhida, tendo em mente, porém, que o que se obteria seriam as narrativas das práticas e percepções dos sujeitos envolvidos e não conteúdos fiéis à prática ${ }^{(7)}$.

Portanto, foram realizadas entrevistas abertas, ou em profundidade, ou seja, o informante era convidado a falar sobre determinado assunto e as perguntas do investigador que permeavam o diálogo eram feitas com o intuito de aprofundamento das reflexões ${ }^{(7)}$.

As entrevistas foram agendadas e ocorreram no local de trabalho dos gestores, em apenas um encontro, separadamente, e em datas distintas. A gravação foi autorizada pelos participantes e os gestores explanaram, livremente, a partir de questões norteadoras, como "Como o serviço é estruturado? Como se dá a relação entre os setores saúde e educação?”.

Os dados foram analisados a partir da Análise do Conteúdo na modalidade de Análise Temática, tendo como plano de fundo a realidade partilhada pelos sujeitos, a surdez como problemática social. Após a transcrição de todo o material, a análise foi delineada a partir de três etapas e possibilitou perceber relações entre as diferentes fontes ${ }^{(7)}$. As etapas sucederam-se da seguinte forma:

- Primeira etapa: foi realizada a leitura flutuante do material, em que o pesquisador teve contato direto com os documentos. Posteriormente, foi constituído o corpus, em que se determinaram as unidades de registro (palavras-chave ou frases), a unidade de contexto (delimitação do contexto de compreensão da unidade de registro), os recortes e a forma de categorização.

As informações foram organizadas com o objetivo de promover a aproximação com os dados e significados revelados nas falas dos sujeitos, estabelecendo núcleos de sentidos.

Logo, foi realizada a integração dos conteúdos por núcleos de sentidos de cada grupo, como tentativa de estabelecer confronto entre os significados revelados nas falas. Após o encontro das divergências, convergências e complementaridades dos núcleos de sentidos, entre os diferentes grupos, foi realizada a leitura exaustiva do material, o que permitiu selecionarmos as categorias empíricas do estudo.

- Segunda etapa: foram criadas categorias de expressões ou palavras significativas, em função das quais o conteúdo de uma fala foi organizado em um quadro, confrontando cada grupo.

- Terceira etapa: foram propostas inferências e realizadas

Quadro 1. Identificação dos sujeitos do Grupo 1

\begin{tabular}{|c|c|c|c|c|c|}
\hline Identificação & Gênero & Idade (anos) & Idade do filho & Escolaridade & Renda mensal (salário mínimo) \\
\hline F1 & Feminino & 23 & 7 & Fund. Incompleto & Até 1 \\
\hline F2 & Feminino & 35 & 8 & Fund. Incompleto & Até 1 \\
\hline F3 & Feminino & 22 & 6 & Fund. Completo & Até 1 \\
\hline F4 & Feminino & 22 & 2 & Fund. Incompleto & Até 1 \\
\hline F5 & Feminino & 29 & \multirow{2}{*}{9} & Fund. Incompleto & 1 à 5 \\
\hline F5.1 & Masculino & 30 & & Fund. Completo & 1 à 5 \\
\hline F6 & Feminino & 22 & \multirow{2}{*}{6} & Fund. Incompleto & Até 1 \\
\hline F6.1 & Masculino & 25 & & Fund. Completo & 1 à 5 \\
\hline F7 & Feminino & 37 & 11 & Fund. Incompleto & Até 1 \\
\hline F8 & Masculino & 26 & 11 & Fund. Incompleto & Até 1 \\
\hline
\end{tabular}

Legenda: Fund. Incompleto = fundamental incompleto; Fund. Completo = fundamental completo 
interpretações do material, relacionando-as com o arcabouço teórico e interpretação dos resultados obtidos com auxílio da fundamentação teórica adotada.

Portanto, foi possível compreender as condições de produção de um dado discurso, fosse ele de um familiar ou de um gestor, marcado na memória social (corpo-histórico-cultural compartilhado) e interpassado pelas várias vozes sociais que puderam ser percebidas na fala de um sujeito.

A pesquisa foi aprovada pelo Comitê de Ética e Pesquisa em Seres Humanos do Hospital de Clínicas da Universidade Federal do Paraná, com registro CEP: 410ext043/2011-10 e os todos os sujeitos assinaram o Termo de Consentimento Livre e Esclarecido, concordando com a sua participação. Anteriormente à submissão do projeto ao comitê, foi solicitada à Secretaria Municipal de Educação e Saúde a autorização para o desenvolvimento da investigação, visto que, o objeto de estudo envolvia os dois setores.

\section{RESULTADOS}

O Grupo 1 foi composto pelas famílias das crianças que fazem parte do centro de atendimento educacional. Setenta por cento dos familiares pertenciam ao gênero feminino, com média de idade de 27,1 anos. No que diz respeito à escolaridade e renda, $70 \%$ tinham ensino fundamental incompleto, com renda de até um salário mínimo e a maioria (40\%) era usuária da mesma unidade de saúde.

Vale ressaltar a caracterização das crianças pertencentes às famílias descritas: a maioria das crianças (cinco crianças, $62,5 \%$ ) abrangia a faixa etária de 6 a 10 anos, enquanto que três crianças (37,5\%), a faixa etária de 1 a 6 anos, sendo $62,4 \%$ do gênero masculino. A maioria apresentava o diagnóstico de perda auditiva sensorioneural bilateral de grau profundo, diagnosticada entre 0 e 3 anos de vida $(62,5 \%)$, de causa idiopática $(62,5 \%)$ e $87,5 \%$ das crianças não foram submetidas ao teste da orelhinha ao nascer. Atualmente, $37,5 \%$ não fazem uso de nenhum tipo de prótese auditiva, enquanto que 37,5\% fazem uso de prótese auditiva bilateralmente e $25 \%$ realizaram Implante Coclear.

O diagnóstico considerado tardio, com média de idade de 3,26 anos na maioria das crianças, pôde ser observado em outros estudos $^{(8)}$. Apenas uma criança encontrava-se em escola especial, enquanto que as demais estavam inseridas em classes comuns de escolas regulares, em processo de aquisição da LIBRAS, o que sugere um movimento de inclusão, fruto das políticas vigentes na área.

O Grupo 2 foi formado pelos gestores locais, servidores estatutários que exerciam cargo de gestão. O Gestor da saúde (G1) possuía formação em enfermagem e especialização em saúde coletiva, atuando no município há oito anos. O Gestor da educação (G2) era graduado em educação física, com experiência na área de inclusão (dados fornecidos durante a entrevista).

Por meio da análise das falas dos sujeitos (recortes), foi possível extrair duas grandes categorias temáticas para discussão: 1 - O diagnóstico precoce, a saúde auditiva como um direito, o acolhimento adequado e orientações iniciais, como uma necessidade; 2 - Dificuldades na relação intersetorial Saúde e Educação.

\section{Frustração no processo de diagnóstico, acolhimento e orientação}

Em seus discursos, as famílias deixaram evidente a falta de acolhimento e fornecimento das orientações iniciais sobre a surdez. O momento do diagnóstico se entrelaçou com os mais variados sentimentos, que tomaram por completo os pais, trazendo sensações de culpa, insegurança e negação, intercaladas por uma busca incessante por outros diagnósticos.

Os gestores demonstraram perceber a importância do diagnóstico de surdez precocemente e, contraditoriamente, o gestor da Saúde indicou que considera a escola como lugar de maior importância na captação de crianças com alterações auditivas.

A falta de conhecimento dos profissionais que atenderam essas crianças, a respeito do desenvolvimento infantil, ficou evidente e pôde ser constatada nas falas dos sujeitos.

A necessidade de realização do teste da orelhinha no município foi colocada pelo gestor responsável e a morosidade para a liberação dos exames e dificuldade para o acesso aos serviços de saúde pôde ser percebida nos relatos.

Em contrapartida à morosidade relatada pelos sujeitos do Grupo I, o gestor da Saúde (G1) referiu-se à marcação e realização do exame básico de audição como "rápido".

Os recortes podem ser visualizados no Quadro 2.

\section{Dificuldades na relação intersetorial - Saúde e Educação}

Nesse segundo eixo temático, as famílias se referiram o desconhecimento dos profissionais da Atenção Básica quanto às ofertas da Secretaria de Educação, como por exemplo, o Centro de Atendimento Educacional existente no município, local da presente pesquisa, e de como tiveram acesso ao centro de atendimento. Os gestores, por sua vez, retrataram a relação dos setores saúde e educação.

Os recortes podem ser visualizados no Quadro 3.

\section{DISCUSSÃO}

A maioria dos sujeitos que compuseram o Grupo Família pertencia ao gênero feminino (70\%). Segundo a literatura, a mãe é a responsável pelos serviços domésticos e pela saúde de seu filho e, em se tratando de uma criança com deficiência, raramente os pais comparecem aos centros de atendimento, ficando toda a responsabilidade para a figura materna, principalmente em famílias com baixo rendimento mensal ${ }^{(8)}$. Neste estudo, três pais participaram ativamente e se mostraram sensíveis 
Quadro 2. Recorte das falas dos sujeitos referentes à Categoria 1

\begin{tabular}{|c|c|c|}
\hline Categoria 1 & Grupo 1 - Família & Grupo 2 - Gestores \\
\hline $\begin{array}{l}\text { Frustração no processo de } \\
\text { diagnóstico, acolhimento e } \\
\text { orientação. }\end{array}$ & 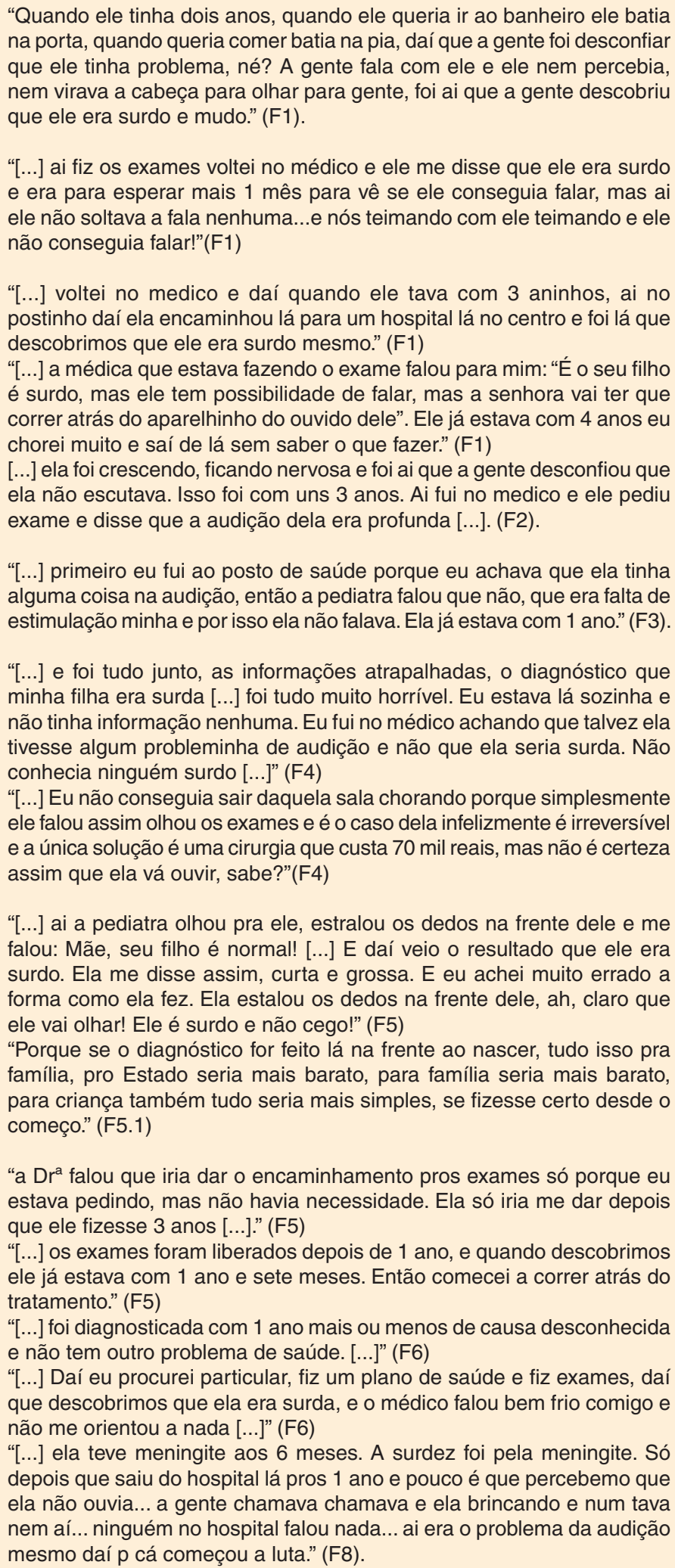 & 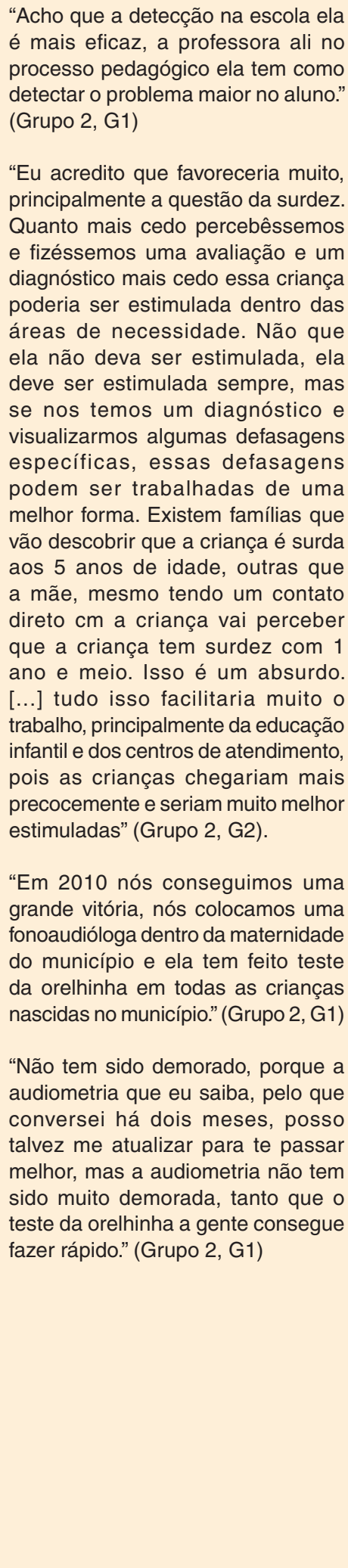 \\
\hline
\end{tabular}

e interessados em todas as consequências de um diagnóstico tardio em seus filhos.

As famílias, em sua maioria, possuíam ensino fundamental incompleto e renda mensal de até um salário mínimo, que no Paraná corresponde, em média, a 700 reais. Em um estudo realizado em cinco maternidades da cidade de Recife, com o 
Quadro 3. Recorte das falas dos sujeitos referentes a Categoria 2

\begin{tabular}{|c|c|c|}
\hline Categoria 2 & Grupo 1 - Família & Grupo 2 - Gestores \\
\hline $\begin{array}{l}\text { Dificuldades na relação intersetorial - } \\
\text { Saúde e Educação }\end{array}$ & 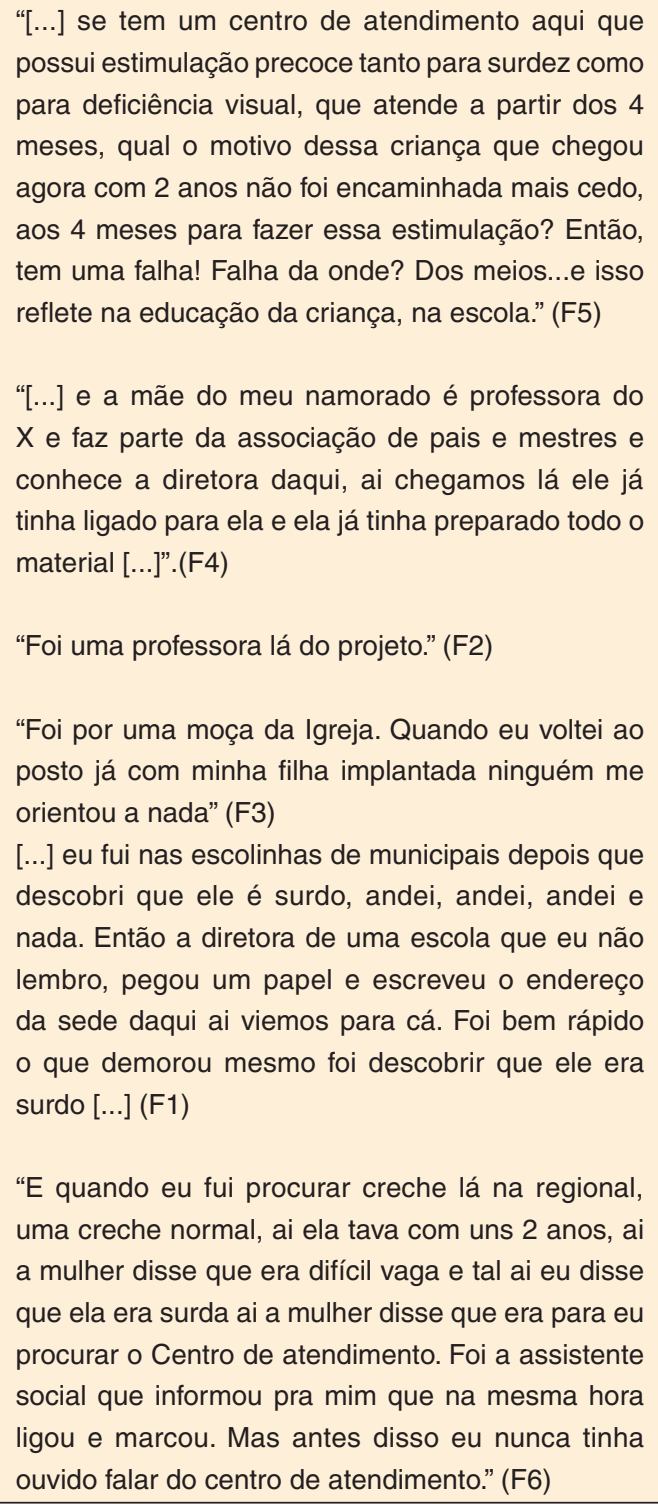 & $\begin{array}{l}\text { "E a nossa relação com a educação é } \\
\text { essa, nós temos uma boa parceria, com } \\
\text { a coordenadora que é psicóloga, quando } \\
\text { ela precisa de consultas nós viabilizamos } \\
\text { isso. Nós temos uma referência em } \\
\text { pediatria com a UB alto Macaranã que é } \\
\text { Dr X, excelente profissional. E quando a } \\
\text { criança tem algum problema auditivo ela } \\
\text { faz uma avaliação e encaminha para a alta } \\
\text { complexidade. Então a educação especial } \\
\text { tem esse acesso fácil, liga direto com a } \\
\text { coordenação e agenda" (G1) } \\
\text { "Não existe uma integração evidente da } \\
\text { área da educação com a área da saúde. } \\
\text { É lógico que a gente caba fazendo alguns } \\
\text { encaminhamentos, quando necessário, } \\
\text { para que a saúde venha a nos apoiar" (G2) }\end{array}$ \\
\hline
\end{tabular}

objetivo de caracterizar o perfil socioeconômico e demográfico de mães que participaram da triagem auditiva neonatal, constatou-se idade superior a 20 anos, ensino médio incompleto e renda familiar baixa, na maioria das participantes. As autoras citam a importância de se conhecer o perfil da população a que se destinam as políticas e projetos locais de saúde auditiva ${ }^{(9)}$.

Alguns estudos retratam que, quanto mais baixo o poder aquisitivo, mais as crianças com surdez apresentam limitações e atribuem isso à dificuldade no acesso aos serviços de reabilitação ${ }^{(10)}$. Outro estudo, retratou que a prevalência da perda auditiva diminui, na medida em que a renda familiar aumenta ${ }^{(11)}$.

As crianças com surdez, pertencentes às famílias anteriormente caracterizadas, em sua maioria, são do gênero masculino e encontram-se na faixa etária de 6 à 9 anos. Todas as crianças apresentam perda sensorioneural de grau profundo bilateralmente e $62,5 \%$ de causa desconhecida. O diagnóstico foi considerado tardio, com média de idade de 3,26 anos na maioria das crianças, que pode ser vista em outros estudos ${ }^{(12)}$ e apenas uma criança encontra-se em escola Especial, enquanto que as demais estão inseridas em classe comum de escolas regulares e estão em processo de aquisição da LIBRAS o que sugere um movimento de inclusão, fruto das políticas vigentes na área.

Em relação à maneira utilizada pelos profissionais de saúde, como por exemplo, ausência de explicações às famílias desta pesquisa ao visualizar o diagnóstico de surdez, um outro estudo, com o objetivo de investigar a vivência de dez mães entre a suspeita, o diagnóstico de surdez e o encaminhamento para habilitação, bem como a percepção delas a respeito da forma como foi atribuído e explicado o diagnóstico, também evidenciou tais fatos em seus dados ${ }^{(13)}$. Os autores concluíram que a comunicação da surdez às famílias, necessitaria levar em consideração as condições sociais, culturais e emocionais dos pais. 
Diante disso, fica evidente a importância do profissional de saúde que faz o diagnóstico da surdez para a família, que muitas vezes se desespera e se perde no sistema de saúde, sem informações e esclarecimentos suficientes. Tal fato foi observado neste presente estudo e vale ressaltar que se tratou de uma realidade local, não podendo ser generalizado para outras localidades.

Sabe-se que no processo da avaliação audiológica, há o momento da devolutiva aos pais, em que são repassadas informações sobre a existência de algum comprometimento auditivo, as características desse comprometimento e as orientações às famílias, em relação às condutas a serem tomadas e devidos encaminhamentos ${ }^{(14)}$. É nesse momento de fragilidade em que o acolhimento e escuta devem se fazer mais presentes, estabelecendo um vínculo de confiança entre o profissional e cuidadores.

O acolhimento, aqui, vem no sentido de estar junto, de "estar com". Vem como um compromisso ético, em que o sujeito se deixa afetar pelo sofrimento do outro e reconhece no outro as “diferenças, dores, alegrias, modos de viver, sentir e estar na vida" (15) e como compromisso político, na disposição de um "estar com" o coletivo.

$\mathrm{Na}$ fala dos familiares foi relatado o "choque", quando os pais ouvintes receberam a notícia de surdez em seu filho. Sabese que o diagnóstico deverá ser informado de forma adequada, evitando a sensação de abandono enfrentada pela família e isso conduzirá às tomadas de decisões e intervenções reabilitadoras, o que proporcionará o melhor desenvolvimento da criança ${ }^{(16)}$.

Ao ter o primeiro contato com a criança após o nascimento, o pediatra se torna corresponsável pela identificação das crianças com suspeitas de alterações auditivas e deve levar em consideração a história clínica e as queixas trazidas pelas mães. Verificou-se que não foi essa a realidade vivida pelos sujeitos deste estudo.

O despreparo dos profissionais da saúde pública em relação à surdez, assim como a falta de ações em saúde auditiva na atenção básica, fatos observados nos relatos dos pais, sugerem a não eficiência das capacitações e orientações aos profissionais, como se preza a PNASA ${ }^{(5)}$.

Sabe-se dos benefícios linguísticos, comunicativos, cognitivos, sociais e emocionais, proporcionados pelo diagnóstico precoce e, diante disso, a sua importância na rotina dos profissionais de saúde ${ }^{(17)}$. Portanto, as ações de promoção podem se tornar um meio eficaz no processo de detecção precoce e devidos encaminhamentos, a partir de um trabalho interdisciplinar e multiprofissional.

Nos dados coletados, o diagnóstico precoce foi colocado como necessário para o bom desenvolvimento infantil e intervenções reabilitadoras, por todos os sujeitos (família e gestores), mesmo por aqueles que não tiveram acesso a informações adequadas e nem aos meios de diagnósticos ao nascer, como o teste da orelhinha na maternidade.

O município em questão possui apenas uma fonoaudióloga atuando na assistência à saúde, 27 equipes de saúde da família e não possui NASF em seu território. E é lá, na Atenção Básica, que deveriam se iniciar as intervenções de saúde auditiva, com a existência de profissionais fortalecendo a integralidade no cuidado à saúde.

A inserção de um profissional fonoaudiólogo na atenção básica poderia ser uma forma de minimizar as imperfeições na promoção, proteção e reabilitação à saúde auditiva e acesso aos exames de diagnóstico ${ }^{(18)}$ e seria possível por meio da criação de um NASF municipal, com equipe interdisciplinar, em que o profissional fonoaudiólogo estivesse presente para viabilizar as estratégias na atenção primária à saúde, como também para estreitar as relações intersetoriais, fortalecendo o que preza a PNASA. Assim também, os profissionais que compõem os Serviços de Atenção à Saúde Auditiva poderiam, a partir de informações, capacitar as equipes na Atenção Básica para identificar a evolução de linguagem saudável da criança e elaborar estratégias para perceber se há algo em desacordo com o desenvolvimento normal da audição, evitando diagnósticos tardios.

Foi possível perceber o desconhecimento de alguns profissionais que acolheram as famílias sobre o desenvolvimento de linguagem, pois consideraram normal a criança falar após 2 anos de idade ou mais e, portanto, não escutaram as queixas trazidas pelos pais e não solicitaram exames de diagnóstico.

Segundo dados da literatura pertinente, as primeiras palavras emitidas por uma criança em seu desenvolvimento normal de linguagem serão a partir do oitavo mês de vida ${ }^{(19)}$, porém apresentam comportamentos comunicativos a partir dos 3 meses, com a presença do sorriso, do olhar e do balbucio. Diante desses elementos, torna-se necessário o encaminhamento de uma criança antes dos 2 anos para avaliação audiológica.

Porém, o que se vê em pesquisas nacionais recentes é um diagnóstico tardio de perdas auditivas em grau profundo, com descoberta em média de idade de 4 anos e 6 meses, em estudo da região Sudeste ${ }^{(12)}$. Em cidade da região Nordeste, um estudo mostra um diagnóstico com idade de 1 ano e 2 meses $^{(20)} \mathrm{e}$ outro estudo, diagnóstico com média de idade de 5,46 anos, na cidade de São Paulo ${ }^{(21)}$. A literatura internacional (EUA) aponta para um diagnóstico precoce aos 2 meses de vida, realizado a partir da triagem auditiva universal, e início de intervenção aos 6 meses $^{(22)}$.

Observou-se, neste estudo, que os resultados sobre os diagnósticos de perda auditiva sensorioneural e sobre a média de idade desses diagnósticos, apesar de não serem frutos de uma pesquisa quantitativa com amostra populacional extensa, se distanciam dos encontrados na literatura internacional e, por sua vez, se aproximam dos dados apontados nos estudos nacionais.

Tais fatos dificultaram a inserção dessas crianças no meio escolar, na escolha da modalidade linguística, nos encaminhamentos aos meios de protetização, acarretando atrasos e desdobramentos importantes no desenvolvimento de linguagem.

Em contrapartida, o gestor local da saúde (G1) falou sobre os avanços da atual gestão, em relação à realização do Teste 
da Orelhinha (terceirização de serviço) desde 2010. Todavia, a PNASA foi implantada em 2004, ou seja, somente após seis anos da implantação da política nacional de saúde auditiva iniciou-se o diagnóstico precoce no município.

A maioria $(62,5 \%)$ das crianças que participou desta pesquisa, compreendia a faixa etária de 6 a 10 anos e apenas uma criança, nascida em 2010, poderia ter sido beneficiada com o teste da orelhinha, na maternidade em que nasceu, porém, tal fato não ocorreu e seu diagnóstico só foi comprovado aos 2 anos de idade.

Como já foi discutido, o diagnóstico precoce de surdez antecede a inserção à pré-escola, que deverá ser entre 4 e 6 anos de idade. Ainda segundo a Lei de Diretrizes e Bases da Educação Brasileira, o início da educação infantil se dá na creche até os 4 anos de idade, porém, segundo o $\mathrm{IBGE}^{(1)}$, as crianças brasileiras ingressam na escola a partir dos 3 anos de idade, idade considerada avançada para que se diagnostique a surdez. Entretanto, vale ressaltar que o exame de emissões otoacústicas passou a ser obrigatório no Estado do Paraná, através de legislação estadual, em 22 de dezembro de $2004^{(5)}$.

Outro fato relatado pelos pais foi a morosidade para marcação dos exames de diagnóstico audiológico, como audiometria tonal, potencial evocado auditivo e emissões otoacústicas e para acesso aos recursos de reabilitação, como próteses auditivas e implante coclear (IC), que são garantidos pela PNASA ${ }^{(5)}$.

Vale ressaltar que não há dados científicos, ou da instituição, que nos forneçam tais informações, mas de acordo com as falas dos sujeitos, a espera foi de, no mínimo, um ano e, no máximo, três anos para liberação de exames de diagnóstico, como também concessão de próteses auditivas. Mesmo assim, alguns pais consideraram como uma aquisição rápida, enquanto que outros buscaram pela rede suplementar ou em outro Estado (São Paulo).

Em outra pesquisa, com base em dados dos prontuários de 22 crianças surdas, em cidade da região Nordeste, o acesso à prótese auditiva se deu quando as crianças estavam com idade de 3,6 anos, em média ${ }^{(20)}$, e em São Paulo, conforme 166 prontuários, iniciaram o uso da prótese auditiva com, aproximadamente, 7 anos de idade ${ }^{(21)}$. Na presente pesquisa, das oito crianças, $37,5 \%$, faziam uso de prótese auditiva e $25 \%$ haviam realizado Implante Coclear. Porém, três crianças $(37,5 \%)$ ainda aguardavam a aquisição de próteses auditivas e, vale ressaltar que, segundo informado pelas mães, a espera é superior a dois anos.

Tais fatos podem ser atribuídos à dificuldade no acesso aos serviços disponíveis, visto que são localizados em outros municípios e não onde os usuários residem, como também à demanda, que ultrapassa os recursos humanos, acarretando um longo tempo de espera, contrariando o que preza a PNASA ${ }^{(5)}$ e a Lei de LIBRAS ${ }^{\circ} 10.436$, instituída em 2002, que garante atendimento prioritário em todos os níveis de complexidade aos alunos matriculados nas redes de ensino da educação básica.

No caso do município local da presente pesquisa, pertencente à região metropolitana de Curitiba - PR, os atendimentos para realização de exames de diagnósticos audiológicos e adaptação de prótese auditiva ocorrem em outro município, responsável pela $2^{a}$ Regional de Saúde, da qual o município em questão faz parte, como também na própria capital do Estado.

São visíveis as dificuldades encontradas pelas famílias do município, estudadas nesta pesquisa. "Disputam" vagas para as marcações de exames de diagnósticos e aquisição de sistemas de amplificação com outros municípios do Estado, pertencentes à mesma Regional de Saúde.

Faz-se pertinente a ampliação da rede de atendimento dos serviços de saúde auditiva, sejam eles exames de diagnóstico ou acesso aos meios de reabilitação, a partir da implantação de um serviço de saúde auditiva no próprio município, ou a por meio da rede complementar e convênios com outras clínicas próximas às residências das famílias.

O gestor da saúde (G1) atribuiu tais dificuldades à falta de investimentos, refletindo um problema generalizado em nosso país, bem como à insuficiência dos repasses financeiros do Estado, insuficientes para cobrir as demandas locais, acarretando nas dificuldades relatadas pelos sujeitos do Grupo 1 .

Contudo, segundo a Lei 8080/90, cabe ao governo municipal e ao Distrito Federal a execução e gerenciamento dos serviços públicos de saúde, sejam eles terceirizados, ou não e ao Governo Estadual e Distrito Federal o acompanhamento, controle e avaliação das redes assistenciais do SUS, assim como o apoio técnico e financeiro aos municípios, dentre outras atribuições.

Faz-se necessária a organização do protocolo de próteses auditivas no domínio do SUS, que busque a atenção integral e eficaz. Para que isso seja possível, devem existir articulações intersetoriais entre as vigilâncias com as redes de assistência, o que proporcionará a comunicação entre os serviços de referência e contrarreferência, fortalecendo a integralidade ${ }^{(23)}$.

Neste sentido, uma ação conjunta requer a visão de um único sistema, que funcione e forneça de maneira integral os serviços que supram as necessidades dos usuários.

As ações intersetoriais são imprescindíveis quando se busca a integralidade da assistência e quando se lança o olhar em importantes consequências que um diagnóstico de surdez tardio acarreta ${ }^{(24)}$.

A falta dessa articulação do sistema pôde ser observada nas falas dos pais que demonstraram perceber que há "alguma falha dos meios e isso reflete na educação da criança". Esses "meios" podem ser entendidos como falta de comunicação entre os serviços de saúde e aqueles oferecidos pela educação.

Baseando-se na Norma Operacional Básica no 01/93, o que se refere a "único", atribuído ao sistema de saúde, "deve ser entendido como um conjunto de elementos de natureza doutrinária ou organizacional". Portanto, os profissionais de saúde, principalmente o fonoaudiólogo, devem ser vistos como vinculados a um conjunto de serviços, reconhecendo o conceito de unicidade do sistema, e não a alguma fragmentação da rede. É necessário que, além do conhecimento do território, haja 
uma visão em rede do sistema e que se busque uma estratégia de comunicação entre os serviços de todas as complexidades pertencentes ao SUS.

Para que isso seja possível, os próprios serviços de saúde precisam estar sensíveis às demandas e conhecer os estabelecimentos disponíveis e sua competência nos diferentes níveis ${ }^{(17)}$, como também proporcionar um tratamento de qualidade por meio de práticas humanizadas, voltando-se ao sentido de saúde como direito de cidadania ${ }^{(25)}$.

É esse conhecimento e atuação em rede que fará a diferença e, a partir dele, as consequências seriam minimizadas, as crianças seriam diagnosticadas precocemente e chegariam mais cedo aos centros de reabilitação.

Quando os pais se referiram aos meios de acesso ao centro de atendimento, ficou evidente a falta dessa articulação, pois mencionaram que tal informação foi transmitida por outras pessoas (professores, amigos) e não pelos profissionais da Atenção Básica, no momento do diagnóstico.

Os mesmos achados também puderam ser vistos numa pesquisa realizada em Salvador (BA), com base em entrevistas com 30 usuários em atendimento fonoaudiológico pelo SUS, em 2006, ou seja, mesmo após seis anos e em regiões com realidades diferentes, os resultados se convergiram, quando a maioria dos participantes relatou ter acesso ao serviço por orientação de pessoas de sua rede social e não por profissionais de saúde ${ }^{(26)}$.

Assim, retornamos ao ponto em que as categorias desta pesquisa dialogaram e que reconhecem na Atenção Básica o local de orientação e encaminhamentos aos centros educativos, respeitando o fluxo e os mecanismos de ajustes de funcionamento. A ideia de redes de ações e serviços de saúde foi redefinida como uma cadeia de cuidado progressivo, que garante a integralidade e a resolução dos processos de atenção à saúde e enxergaram a integralidade como principal suporte organizacional da gestão das ações em saúde ${ }^{(25)}$. Os gestores da saúde (G1) e educação (G2), por sua vez, citaram a tentativa de relação de proximidade entre as secretarias, algo que é vivenciado informalmente e restringe-se à viabilização da saúde quanto à marcação de exames e consultas complementares de crianças já inseridas na escola e à possível criação de um comitê (G2).

O Plano Viver sem Limites ${ }^{(27)}$ ressalta a necessidade da comunicabilidade intersetorial e prioriza, dentre outras metas que focam a saúde, inclusão e qualidade de vida da pessoa com deficiência, por meio da atuação com base na Rede de Cuidados à Pessoa com Deficiência. Coloca como pontos importantes o desenvolvimento de ações intersetoriais de promoção e prevenção à saúde, a divulgação das informações sobre os serviços disponíveis na rede, a regularização das demandas e fluxos assistenciais da rede e a construção de indicadores para monitoramento e avaliação dos serviços, como também, a resolubilidade da atenção à saúde, dentre outras providên$\operatorname{cias}^{(27)}$. O Paraná divulgou a sua adesão ao plano em agosto de 2012 e, portanto, as mudanças em relação às dificuldades apresentadas pelos pais podem vir a ser minimizadas, ou até mesmo solucionadas, na medida em que a gestão competente exerça o que o decreto determina.

Vale ressaltar que as entrevistas realizadas com os gestores (G1 e G2) antecederam a data em que o Estado aderiu ao Plano Nacional, o que pode justificar o fato da gestão não mencionar qualquer movimento em relação à implantação da rede no município.

Logo, a simples facilitação na marcação de consultas, que já é algo garantido e visto como prioridade pelas políticas e leis anteriormente citadas, não deve ser o único meio de comunicação entre os setores de educação e saúde. Os ministérios e secretarias estaduais e municipais devem garantir a assistência de forma articulada e não fragmentada com ações pontuais e políticas setoriais. Assim, a complexidade da deficiência auditiva, reconhecida a partir das demandas apresentadas, necessita de ações do Sistema de Saúde nos diversos níveis de atenção ${ }^{(23)}$.

Alguns autores relatam que muitas das medidas intersetoriais acontecem informalmente, sem planejamento prévio, com ações estabelecidas por apenas um setor, contrariando os ideais da intersetorialidade. Diante disso, faz-se necessário o diálogo constante entre os setores, por meio de vínculos de corresponsabilização e cogestão, para que sejam planejadas e programadas atividades diferenciadas, em que haja o compartilhamento de gestão e de articulação de saberes e ações das instituições envolvidas ${ }^{(28)}$.

É necessário refletir sobre esse novo desafio da elaboração de propostas que envolvam a visão de integralidade, abrangendo ações intersetoriais nas áreas de educação e saúde, tendo como base a Constituição Federal (1988), que determina competências e compromissos das esferas governamentais ${ }^{(29)}$.

Outros autores ${ }^{(29)}$ também discorrem sobre as áreas de competência de algumas políticas intersetoriais, com atenção integral em diferentes ciclos de vida e atribuem a participação ativa da saúde e educação às ações de promoção e proteção da saúde, habilitação, reabilitação, serviços de informação e orientação.

E assim, tecendo nossas aproximações do campo da integralidade com os desdobramentos da surdez, um dos caminhos possíveis seria a reorganização das instituições de saúde com relação a possibilidades de projetos políticos integradores e organizativos de práticas voltadas ao ensino, pesquisa e funcionamento dos serviços, em nível local ${ }^{(25)}$.

Reforça-se, também, a importância do cuidado que devem ter os profissionais de saúde, para possibilitar apoio às famílias e a possibilidade de um diagnóstico precoce, assim como os devidos encaminhamentos após a constatação da surdez de uma criança.

Portanto, este estudo, mesmo que tenha refletido uma realidade local, forneceu contribuições para possíveis reflexões quanto ao fato de que as vivências expressas pelas famílias podem ainda ser comuns a outros sujeitos e que mudanças nas redes de atenção são necessárias. 


\section{CONCLUSÃO}

Foi possível evidenciar neste estudo que o acolhimento foi insatisfatório e que as orientações iniciais após o diagnóstico de surdez não foram adequados. O princípio da integralidade não foi plenamente contemplado, visto que, a espera da liberação de exames de diagnóstico e meios de reabilitação auditiva foi superior a um ano, configurando-se como fator prejudicial na intervenção precoce e, consequentemente, no desenvolvimento das crianças. Não existe, no município local do estudo, uma relação intersetorial (saúde e educação) satisfatória, nem o funcionamento em redes de atenção à saúde, visto que, os responsáveis pelas crianças com surdez foram, em sua maioria, encaminhados ao centro de atendimento por outras pessoas e não por meio do SUS logo após o diagnóstico.

Vale ressaltar que estas conclusões referem-se a uma realidade local e que não devem ser generalizadas.

\section{REFERÊNCIAS}

1. Brasil. Ministério do Planejamento, Orçamento e Gestão. IBGE Instituto Brasileiro de Geografia e Estatística. Censo Demográfico 2010. Características gerais da população, religião e pessoas com deficiência. Ministério do Planejamento, Orçamento e Gestão: Rio de Janeiro; 2010.

2. Olusanya BO. Addressing the global neglect of childhood hearing impairment in developing countries. PloS Med. 2007;4(4):e74.

3. Guefier BC, Siqueira MP. O teste da orelhinha. Vida saúde. 2009;2(2):36-7.

4. Lewis DR, Marone SAM, Mendes BCA, Cruz OLM, Nóbrega M. Comitê multiprofissional em saúde auditiva: COMUSA. Braz J Otorhinolaryngol. 2010;76(1):121-8.

5. Brasil. Ministério da Saúde. Portaria 2.073, de 28 de setembro de 2004. Política Nacional de Atenção à Saúde Auditiva. Brasília: Ministério da Saúde, 2009.

6. Mazza VA, Melo NSFO, Chiesa AM. O grupo focal como técnica de coleta de dados na pesquisa qualitativa: relato de experiência. Cogitare Enferm. 2009;14(1):183-8.

7. Minayo MCS. Análise qualitativa: teoria, passos e fidedignidade. Ciênc Saúde Coletiva. 2012;17(3):621-6.

8. Sigolo C, Lacerda CBF. Da suspeita à intervenção em surdez: caracterização deste processo na região de Campinas/SP. J Soc Bras Fonoaudiol. 2011;23(1):32-7.

9. Brito AMW, Dessen MA. Crianças surdas e suas famílias: um panorama geral. Psicol Reflex Crit. 1999;12(2):429-45.

10. Lima MLLT, Assis ABR, Mercês GB, Barros PF, Griz SMS. Triagem auditiva: perfil socioeconômico de mãe. Rev CEFAC. 2008;10(2):254-60.

11. Oliveira RG, Simionato MAW, Negrelli MED, Marcon SS. A experiência de famílias no convívio com a criança surda. Acta Sci Health Sci. 2004;26(1):183-91.

12. Béria JU, Raymann BCW, Gigante LP, Figueiredo ACL, Jotz G, Roithman R, et al. Hearing impairment and socioeconomic factors: a population-based survey of an urban locality in southern Brazil. Rev Panam Salud Pública. 2007;21(6):381-7.

13. Silva ABP, Pereira MCC, Zanolli ML. Surdez: da suspeita ao encaminhamento. Rev Paul Pediatr. 2012;30(2):257-62.

14. Northern JL, Downs MP. Audição em crianças. São Paulo: Manole; 1989.

15. Santos IMV, Santos AM. Acolhimento no Programa Saúde da Família: revisão das abordagens em periódicos brasileiros. Rev Salud Pública. 2011;13(4):703-16.

16. Silva SF. Experiências e necessidades de mães após o diagnóstico de deficiência mental do filho [dissertação]. São Carlos: Universidade Federal de São Carlos; 1988.

17. Alvarenga KF, Gadret JM, Araújo ES, Bevilacqua MC. Triagem auditiva neonatal: motivos da evasão das famílias no processo de detecção precoce. Rev Soc Bras Fonoaudiol. 2012;17(3):241-7.

18. Fernandes TL, Nascimento CMB, Sousa FOS. Análise das atribuições dos fonoaudiólogos do NASF em municípios da região metropolitana do Recife. Rev CEFAC. 2011;15(1):153-9

19. Pedroso FS, Rotta NT, Danesi MC, Avila LN, Savio CB. Evolução das manifestações pré-linguísticas em crianças normais no primeiro ano de vida. Rev Soc Bras Fonoaudiol. 2009;14(1):22-5.

20. Carvalho LS, Cavalheiro LG. Detecção precoce e intervenção em crianças surdas congênitas inseridas em escolas especiais da cidade de Salvador/BA. Arq Int Otorrinolaringol. 2009;13(2):189-94.

21. Pinto MM, Raimundo JC, Samelli AG, Carvalho ACM, Matas CG, Ferrari GMS, et al. Idade no diagnóstico e no início da intervenção de crianças deficientes auditivas em um serviço público de saúde auditiva brasileiro. Arq Int Otorrinolaringol. 2012;16(1):44-9.

22. Yoshinaga-Itano C. Levels of evidence: universal newborn hearing screening (UNHS) and early hearing detection and intervention systems (EHDI). J Commun Disord. 2004;37(5):451-65.

23. Teixeira CF. Estudo avaliativo da Política de Atenção à Saúde Auditiva: estudo de caso em Pernambuco [tese]. Recife: Centro de Pesquisa Aggeu Magalhães. Fundação Oswaldo Cruz; 2007.

24. Bevilacqua MC, Morettin M, Melo TM, Amantini RCB, Martinez MANS. Contribuições para análise da política de saúde auditiva no Brasil. Rev Soc Bras Fonoaudiol. 2011;16(3):252-9.

25. Pinheiro R, Mattos RA. Gestão em redes: práticas de avaliação, formação e participação na saúde. Rio de Janeiro: CEPESC; 2006.

26. Bazzo LMF, Noronha CV. A ótica dos usuários sobre a oferta do atendimento fonoaudiológico no Sistema Único de Saúde (SUS) em Salvador. Ciênc Saúde Coletiva. 2009;14(Supl. 1):1553-64.

27. Brasil. Ministério da Saúde. Gabinete do Ministro. Portaria $n^{\circ}$ 793, de 24 de abril de 2012. Institui a Rede de cuidados à pessoa com deficiência no âmbito do Sistema Único de Saúde. Brasília: Ministério da Saúde, 2012

28. Westphal MF, Mendes R. Cidade saudável: uma experiência de interdisciplinaridade e intersetorialidade. Rev Adm Pública. 2000;34(6):47-61.

29. Balieiro CRB, Trenche MCB. Fonoaudiologia e Inclusão Social. In: Fernandes FDM, Mendes BCA, Navas ALPGP (Orgs.) Tratado de Fonoaudiologia. São Paulo: Roca; 2009. p. 627-33. 